\title{
Tumor Findings Reason Not Done
}

National Cancer Institute

\section{Source}

National Cancer Institute. Tumor Findings Reason Not Done. NCI Thesaurus. Code C119935.

The explanation given as to why a tumor findings assessment was not performed. 